\title{
Poder local e o funcionamento do comércio vicinal na cidade de São Paulo (1765-1822)
}

Denise A Soares de MOURA*

\begin{abstract}
RESUMO: Este texto apresenta algumas hipóteses e idéias sobre o comércio de abastecimento da cidade de São Paulo, entre os anos 1765-1822, através de dados quantitativos e qualitativos levantados em dois conjuntos documentais produzidos pelo Senado da Câmara: Atas e Papéis Avulsos. Este comércio é entendido como um dos circuitos do organismo colonial, conforme proposto por José Roberto do Amaral Lapa. Neste sentido, vem sendo constatado seu funcionamento autônomo, de acordo com os fluxos do mercado interno, as ações dos negociantes-arrematadores de contratos e as reações do Senado da Câmara de São Paulo para enfrentar seus contextos de crise e a radicalização de relações de poder em torno deste circuito mercantil, como fator desencadeador de disputas e hostilidades entre interesses políticos locais, negociantes-arrematadores e autoridades régias.
\end{abstract}

PALAVRAS-CHAVE: comércio interno; poder local; negociantes.

Este artigo apresenta algumas hipóteses sobre o comércio de abastecimento da cidade de S. Paulo, controlado pelo Senado da Câmara, no período de 1765-1822, que vem sendo levantadas e investigadas por uma pesquisa mais ampla intitulada "Poderes locais e mercado interno em São Paulo".

0 recorte cronológico escolhido justifica-se por representar um momento favorável para a pesquisa sobre o comércio colonial no Brasil, devido aos estímulos promovidos pelo caráter de reordenamento da política econômicoadministrativa do Estado português sobre suas possessões ultramarinas, no contexto da crise do Antigo Regime. 
No que diz respeito à história da capitania de São Paulo, este processo mais largo de crise do Antigo Regime, e a forma que assumiu na política do Estado português em relação às suas colônias, $^{2}$ coincidiu com a restauração da autonomia administrativa perdida em 1748, em virtude de conflitos e disputas entre paulistas e autoridades metropolitanas em relação ao trânsito e controle das zonas auríferas das capitanias de $\mathrm{M}$ inas Gerais, M ato Grosso e Goiás.

0 processo da restauração, em 1765, pode estar relacionado a uma política de pressões da Câmara de São Paulo. ${ }^{3}$ $\mathrm{N}$ a documentação camerária deste ano, englobando Atas e Papéis Avulsos, não foram identificadas manifestações desta instituição neste sentido. Contudo, a condição de Senado, alcançada em 1711, antes portanto da perda da autonomia da capitania, sugere que o poder e prestígio desta instância não eram desprezíveis, capacitando-a como importante instrumento de pressão e detentora de interesses específicos no período.

O comércio de abastecimento da cidade de São Paulo era um destes campos de interesse, e para compreender seu funcionamento e articulação com as instâncias locais de poder, o método de análise empregado foi sendo elaborado através dos problemas apresentados pelo levantamento de dados. Deste modo, inúmeras vezes foi necessário retomar a documentação, tendo em vista uma informação ou questão nova e mais enfática surgida no andamento da pesquisa.

Os dados levantados apresentaram a possibilidade e a necessidade de serem analisados qualitativa e quantitativamente. Os dois conjuntos documentais utilizados Atas da Câmara e Papéis Avulsos - foram fartamente investigados e fizeram parte de obras bastante conhecidas sobre a história da cidade de São Paulo. ${ }^{4}$ No entanto, dado o caráter serial de alguns dados que continham, foi possível fazer uso do recurso quantitativo para levantar algumas hipóteses sobre os contextos de prosperidade, crise e reações do comércio de abastecimento da cidade.

Os dados quantitativos, contudo, têm limitações, trazem indicadores, apresentam problemas que devem ser explicados e não conseguem mensurar as reações dos grupos sociais inseridos 
nos problemas que eles apontam. Diante disto, a análise dos dados qualitativos das fontes, ou seja, o cruzamento com as informações dos requerimentos e ofícios camerários possibilitou levantar algumas idéias e melhor compreender os indicadores quantitativos. $^{5}$

Partindo da concepção de sistema colonial proposta por José Roberto do Amaral Lapa, compreende-se o comércio de abastecimento como um dos circuitos do organismo M etrópolecolônia, ou melhor, o circuito que será denominado vicinal, envolvendo uma mesma vila ou cidade e suas freguesias. ${ }^{6}$ Este circuito, portanto, diferencia-se do inter-regional, que ocorria entre vilas com câmaras próprias e entre capitanias.

Ainda com base nas sugestões desse autor, considera-se que este circuito vicinal de comércio, ligado ao abastecimento da cidade de São Paulo e suas freguesias gerou a radicalização de interesses específicos, relacionados menos à maximização de interesses econômicos, mas políticos, vinculados à manutenção da soberania e ao status do Senado da Câmara.

Neste caso, entende-se que os grupos articulados no Senado se uniram para a defesa de interesses próprios e remoção de obstáculos; agiram implícita ou explicitamente de modo a reivindicar e fazer prevalecer esses interesses, criaram formas de pressão direta ou indireta sobre as autoridades metropolitanas, visando a satisfazer seus objetivos ou fortalecer sua capacidade de competição com outros grupos econômico-sociais, ou ampliar sua margem de controle sobre o mercado, ${ }^{7}$ não necessariamente para maximizar sua margem de lucro, mas para hipertrofiar sua margem de poder local.

Considera-se ainda a possibilidade de estes interesses dizerem respeito à preservação de uma "cadeia infinita de atos beneficiais" a que Ângela Xavier e António Hespanha chamaram "economia moral do dom", que mediava as relações sociais e de poder na época moderna. ${ }^{8}$ A lógica dar-receberretribuir/restituir, conforme afirmam, cimentava "a natureza das relações sociais e, a partir destas, das próprias relações políticas". A "economia moral do dom" estava na base de várias ações informais de poder e na elaboração de mecanismos próprios do universo político. ${ }^{9}$ 
Através da comunicação pelo dom, benfeitor e beneficiado inseriam-se numa economia de favores, benefícios e obrigações não necessariamente de valor econômico, mas também simbólico, envolvendo atos de gratidão e serviço.

As Câmaras, como instituições da época moderna, estavam inseridas nessa cadeia de atos obrigacionais-benefíciosfavores, pois em nome do bem comum da República deveriam garantir 0 abastecimento dos súditos do Reino. ${ }^{10}$ Segundo $M$ aria Yedda Linhares, garantir a subsistência de seus vassalos sempre foi preocupação central da Coroa, existindo, inclusive, extensa legislação sobre 0 assunto. ${ }^{11} \mathrm{O}$ abastecimento tanto era uma fonte de recursos e de poder político para a instância municipal, como uma obrigação moral que costurava a relação de benfeitorbeneficiado existente na sociedade de Antigo Regime do BrasilColônia.

M uitos documentos camerários expressam a aflição das autoridades locais em relação às dificuldades de abastecimento da população, em virtude de carestia, dificuldades de arrematação dos contratos de corte da carne, desvios de cargueiros de alimentos para outros mercados, como o da vila de Santos, Rio de Janeiro ou Goiás.

No problema do abastecimento da cidade, portanto, as Câmaras preocupavam-se quando algum ato da lógica do darreceber-retribuir/restituir não estava sendo devidamente cumprido, tendo em vista as implicações que isto poderia ter para a perda do seu poder político e prestígio. Por conseguinte, não é recomendável que a investigação sobre os circuitos vicinais de comércio se restrinjam a noções como acumulação, fortuna, enriquecimento.

Ilana Blaj, pesquisando a dinâmica e o caráter mercantil da sociedade paulista da primeira metade do século XVIII, classificou-a como estamental-escravista, permeada por determinados valores que, na realidade, compunham a unicidade estrutural da formação social brasileira. Assim, símbolos de prestígio e honrarias, a propriedade, a escravidão eram elementos básicos da sociedade colonial brasileira e paulista ${ }^{12}$ e estavam inseridos na lógica do dar-receber-retribuir/restituir. 
N as capitanias e vilas, como em São Paulo, estruturaramse sociedades extremamente hierarquizadas e, portanto, fortemente inigualitárias, afeitas ao visual como meio de afirmação das diferenças sociais. ${ }^{13}$ Entre as três principais despesas do Senado, como pode ser observado na tabela abaixo, as festas abocanhavam boa parte da receita, ocupando, na maioria das vezes, o segundo lugar das despesas totais e superando os gastos com ordenados e propinas, o que sugere ressonâncias de mecanismos de distinção, hierarquização e prestígio próprios de sociedades de Antigo Regime.

TABELA 1 - Despesas da Câmara produzida através do levantamento de dados nos papéis avulsos (1804-1821)

a) $1804-1811$

\begin{tabular}{lcccccc}
\hline Despesas & $\mathbf{1 8 0 4}$ & $\mathbf{1 8 0 5}$ & $\mathbf{1 8 0 7}$ & $\mathbf{1 8 0 8}$ & $\mathbf{1 8 1 0}$ & $\mathbf{1 8 1 1}$ \\
\hline $\begin{array}{l}\text { Obras } \\
\text { públicas }\end{array}$ & $669 \$ 760$ & $1: 346 \$ 057$ & $307 \$ 940$ & $2: 236 \$ 440$ & $1: 046 \$ 935$ & $1: 100 \$ 190$ \\
Festas & $\mathbf{7 1 5 \$ 6 4 0}$ & $\mathbf{5 9 6} \$ \mathbf{2 6 0}$ & $\mathbf{4 4 8} \$ \mathbf{5 2 5}$ & $552 \$ 560$ & $\mathbf{5 2 3 \$ 2 4 0}$ & $\mathbf{6 8 0} \$ \mathbf{3 7 5}$ \\
& & & & & & \\
$\begin{array}{l}\text { Ordenados } \\
\text { e propinas }\end{array}$ & $732 \$ 840$ & $362 \$ 904$ & $400 \$ 800$ & $1: 081 \$ 744$ & $508 \$ 069$ & $370 \$ 958$ \\
\hline
\end{tabular}

b) $1813-1821$

\begin{tabular}{lcccc}
\hline Despesas & $\mathbf{1 8 1 3}$ & $\mathbf{1 8 1 4}$ & $\mathbf{1 8 1 5}$ & $\mathbf{1 8 2 1}$ \\
\hline Obras públicas & $1: 811 \$ 863$ & $2: 155 \$ 200$ & $1: 716 \$ 435$ & $1: 671 \$ 990$ \\
Festas & $\mathbf{6 7 2 \$ 2 1 3}$ & $\mathbf{9 1 0} \$ 280$ & $477 \$ 890$ & $\mathbf{1 : 2 7 0 \$ 1 4 0}$ \\
$\begin{array}{l}\text { Ordenados e } \\
\text { propinas }\end{array}$ & $397 \$ 400$ & $700 \$ 000$ & $686 \$ 220$ & $655 \$ 996$ \\
\hline
\end{tabular}


Qualificação/requalificação, nobilitação, prestígio eram elementos que faziam parte da sociedade de Antigo Regime português e que se estendiam aos seus impérios ultramarinos, ajeitando-se a condições inéditas, como a necessidade premente de ocupar produtivamente vasto território e a miscigenação indígena e africana que fazia da pureza de sangue uma quimera.

Para a metrópole, a consolidação destes valores foi essencial para garantir o domínio de novas terras, sua exploração, a tributação, a obediência dos vassalos, um nível mínimo de ordem que garantisse a governabilidade. 0 ouro das M inas Gerais foi achado e explorado à custa de muitos benefícios concedidos aos paulistas, assim como o extermínio e a conquista de muitos índios rebeldes nos primeiros tempos da colonização. Ao contrário da tradição portuguesa, no Brasil-Colônia o benefício do enobrecimento era recompensa por todo esforço que visasse à ampliação dos domínios e riquezas metropolitanas. ${ }^{14}$

Assim, cargos camarários, o Juizado de Orfãos, postos de poder e prestígio como os de capitão-mor, irmandades e confrarias, titulações militares-religiosas tornaram-se reduto daqueles que iriam compor a elite na colônia ou a nobreza, conforme classificação empregada por Maria Beatriz Nizza da Silva.

Nobreza não necessariamente coincidia com riqueza. Indivíduos ricos evidentemente tinham maior facilidade para alcançar nobilitação, mas havia nobres com bens patrimoniais insignificantes. ${ }^{15} \mathrm{Na}$ sociedade de Antigo Regime, essencial era manter um estilo de vida nobre, como não exercer ofícios mecânicos, servir-se com criado, andar a cavalo, portar armas de fogo ou ponta, estampar patente militar ou formas de tratamento específicas - Dom, Senhorio, Excelência, etc. -, usufruir de graça ou mercê concedida pela vontade do rei.

Ocupar "cargos da República", ou seja, na Câmara M unicipal, principalmente os eleitos, era uma forma de distinção e enobrecimento, garantido apenas aos ditos "homens bons", naturais da terra, o que foi motivo de muitos conflitos com a elite de negociantes, geralmente de origem reinol. 
Assim como os indivíduos, as câmaras também usufruíam certos privilégios, como o de atingir a condição de Senado. Nem todas as câmaras alcançaram o mesmo prestígio - só o tiveram as de Salvador, Rio de Janeiro, São Paulo e São Luís - e algumas aspiraram ao benefício da mesma graça, como a da vila de Santo Antônio de Sá, sob alegação de que muitos que ali residiam eram "moradores de conhecida nobreza". ${ }^{16}$

A Câmara elevada a Senado garantia ao seu corpo de oficiais privilégios e liberdades compatíveis às dos cidadãos portugueses, como condição de fidalguia no caso de prisão, uso livre e indiscriminado de armas, os que vivessem com os camaristas não seriam submetidos a recrutamento militar, e isenção de todo tipo de confiscos. ${ }^{17}$

Como retribuição aos serviços prestados nas guerras contra os índios e na conquista de terras e minas metalíferas, São Paulo obteve a condição de sede administrativa da capitania e de Senado em 1711, status mantido mesmo em 1748, quando a capitania perdeu a autoridade para manter um governo-geral e militarmente passou a ser administrada pelo governador da Praça de Santos, submetido à jurisdição do governador do Rio de Janeiro.

As Câmaras, portanto, estavam inseridas na cadeia de atos beneficiais do Antigo Regime, prolongando do Reino à Colônia uma rede de poder e hierarquias permeada por valores próprios de uma ordem aristocrática e a lógica do dar-receberretribuir/restituir.

Há certo tempo, a historiografia portuguesa e brasileira vem se dedicando ao estudo das Câmaras M unicipais no Império colonial português. Já na década de 60 do século XX, Charles Boxer afirmava que "entre as instituições características do império marítimo português e que ajudaram a manter unidas suas diversas colônias, havia o Senado da Câmara..." que junto com as irmandades podiam ser considerados "pilares gêmeos da sociedade colonial do M aranhão até M acau". ${ }^{18}$

Em Portugal, a pesquisa sobre os conselhos camerários permitiu reinterpretar a tese do caráter demiúrgico do Estado português. Nuno Gonçalo admitiu que as Câmaras foram a 
contrapartida do poder absoluto, abrandado pelo vigor relativo das autonomias locais. ${ }^{19}$

Embora teoricamente os conselhos camerários estivessem sujeitos a inspeções periódicas - a correições, como aparece na documentação -, realizadas pelo corregedor da comarca ou juiz de fora, a Coroa portuguesa não conseguiu exercer controle muito rígido sobre eles, que ainda mantiveram larga margem de autonomia, inclusive para continuar administrando a tributação local até 1822, conforme reconheceu o próprio historiador inglês Charles Boxer. ${ }^{20}$

Caio Prado Jr., embora atribuindo às Câmaras papel de "mero departamento administrativo" subordinado ao governogeral, em certo momento enfatizou a importante característica de possuírem patrimônio, finanças próprias e possuírem "uma quase personalidade jurídica", concluindo que estas condições podem ter determinado a força para mais tarde, na movimentação da Independência, agirem nos sucessos da constitucionalização, Independência e fundação do Império, sendo ainda o único órgão que sobreviveu, mesmo com a crise das instituições coloniais, ${ }^{21}$ algo, contudo, que pode ser admitido até pelo menos 1841, quando ocorreu a reforma do Código do Processo e a consolidação do Centralismo Saquarema.

Inúmeras pesquisas realizadas pela historiografia brasileira vêm comprovando estes níveis de autonomia e força jurídicopolítica das Câmaras Municipais. Ilana Blaj definiu a relação entre autoridades reais, a Coroa e os paulistas - representados pelo Senado da Câmara - como "pendular", nunca chegando a pôr em risco a empresa colonial como "empresa em conjunto". ${ }^{22}$

$M$ aria Fernanda Bicalho concluiu que o fato de as Câmaras coloniais, além de administrarem os impostos criados pela M etrópole, lançarem por sua própria conta taxas e arrecadações, demonstra sua tendência ao autogoverno, algo, todavia, que considera impensável a partir da centúria seguinte, devido ao cerceamento dos poderes - especialmente financeiros - dos Conselhos Municipais imposto pelo Estado português, como a instauração do cargo de juiz de fora - ou seja, não eleito pela municipalidade, mas nomeado pela autoridade real do governo- 
geral - a partir do início do século XVIII ea passagem da maioria dos contratos e tributos administrados pelas municipalidades para a jurisdição da Fazenda Real. ${ }^{23}$

A manutenção do controle, administração e tributação do circuito vicinal de comércio, contudo e especialmente em núcleos urbanos em crescimento populacional, expansão econômica e ocupando posição de centro administrativo de capitanias, não significou pouco. Ao contrário, possibilitou o fortalecimento da instância municipal de poder, de interesses socioeconômicos locais, que inclusive rivalizaram com interesses metropolitanos representados nas autoridades imediatas e, em certa medida, na emergente elite de negociantes vinculados às atividades mercantis subordinadas à Junta da Real Fazenda.

$\mathrm{Na}$ cidade de São Paulo este circuito, formado por contratos arrematados no Senado da Câmara, era dividido em quatro ramos principais: corte do açougue, casinhas, aguardente e estancos das freguesias.

Também chamado de talho municipal, o corte do açougue gerava receitas municipais e o pagamento de subsídio literário para o Real Erário. Um negociante arrematava o direito de corte das rezes no açougue público da cidade, pagava um valor determinado para a Câmara na ocasião do arremate. Todo criador deveria levar suas rezes para serem cortadas nesse local, pagando meia a uma pataca por cabeça de rês cortada. 0 cumprimento desta determinação, porém, não foi rigoroso, gerando reclamações de arrematadores, desestímulo para arrematar contratos e medidas da Câmara visando a combater 0 corte clandestino da carne e animar as arrematações do açougue da cidade.

Em 1767 o negociante Cabral arrematou o corte por $65 \$ 000$ e vendeu a arroba a 14 vinténs. A vereança de 14/12/1799 dizia que o corte do açougue andava em praça há meses e não apareciam arrematadores. Resolveu diminuir pela metade 0 imposto sobre cada rês abatida e elevou a venda da arroba de $\$ 400$ para $\$ 480$, valor, portanto, bem superior ao de 1767 , o que pode sugerir elevação da demanda pelo produto, diminuição de sua oferta, por razões que podem dizer respeito ao desvio para outros mercados, que ofereciam condições de remuneração 
melhor ou pressões dos arrematadores para ampliar sua margem de ganho no comércio vicinal da carne.

Diminuir o imposto do abate e aumentar o valor de venda do produto estimulava o criador a levar suas reses para o corte no açougue da cidade e favorecia a perspectiva de ganho dos arrematadores do corte no momento de venda da carne. Toda a carne gerada do corte das reses no açougue era arrobada, ou seja, pagava o imposto correspondente ao subsídio literário cobrado pelo escrivão do Senado. ${ }^{24}$ Assim, a carne gerava recursos de âmbito local e régio, sendo importante fonte geradora de recursos e aglutinadora de interesses.

As casinhas eram o mercado público da cidade, centralizando a venda a varejo desde 1773, e eram arrematadas anual mente por um interessado que sublocava seus quartos (total de 15) aos vendedores. M uitas vezes estes vendedores se reuniam em dois, em uma casa, para vender suas mercadorias, que compreendiam panos de toicinho, banhas, cargas de mantimentos, açúcar. ${ }^{25}$

Algumas pessoas de prestígio na cidade, e que tinham dívidas ativas com o Senado, se favoreciam das rendas do aluguel das casinhas. 0 sargento-mor Jerônimo de Castro Guimarães, responsável pela construção desses estabelecimentos, os recebeu por dois anos, e em 1775, Luiz de Campos, que reclamava à Câmara o pagamento de juros de uma importância de $300 \$ 000$ que emprestara para as festas do Corpo de Deus e "nascimento do sereníssimo príncipe nosso senhor", passou a receber as rendas das casinhas após ter reclamado com 0 capitão general dom Luiz Antonio de Sousa Botelho M ourão. ${ }^{26}$

Os estancos eram monopólios de venda de bebidas e comestíveis nas freguesias da cidade. Um quadro organizado pelo Morgado de Mateus e enviado ao conde de Oeiras em 1767 mostra que as receitas municipais da cidade de São Paulo $(666 \$ 511)$ eram superiores ao de outras vilas da capitania como Santos, 311\$966; Itu, 154\$760; Sorocaba, 146\$130; Parnaíba, $117 \$ 941 ;$ J undiaí, $107 \$ 473$. $^{27}$

0 almotacé, cargo criado em 1532, era o funcionário eleito mensalmente pela Câmara que controlava esse circuito, impondo 
valores das taxas, fiscalizando o abastecimento de víveres da cidade e suas freguesias, fazendo cumprir as determinações do Conselho; devia processar as penas pecuniárias impostas pela Câmara aos moradores, despachar rapidamente os feitos, sem grandes processos e escrituras; dar apelação e agravo para os juízes sobre qualquer feito que despachassem; devia repartir a carne dos açougues entre os moradores; aferir mensalmente com o escrivão da al motaçaria os pesos e medidas. ${ }^{28}$

Ao longo de um ano, geralmente a Câmara contava com 4 a 7 almotacés, que recebiam por almotaçaria, ou seja, por selo ou marca que punha numa venda, entendida como o conjunto dos gêneros de um arrematador ou vendedor. Em 1777, um almotacé recebia por mês $\$ 80$ de cada almotaçaria, independentemente da quantidade de gêneros que almotaçava. ${ }^{29}$

A expansão do mercado de abastecimento da cidade, a saber, a efetiva necessidade de gêneros alimentícios e seu fornecimento oficial, via arrematação de contratos ou vendas fixas, em vez da comercialização informal e ambulante, interessava a este oficial pela remuneração que poderia lhe proporcionar.

Segundo Nizza da Silva, cargos como esse eram ocupados por oficiais de ofício, como alfaiate, armeiro, artilheiro, caldereiro, carpinteiro, coureiro, curtidor, espadeiro, ferreiro, latoeiro, marceneiro, ourives, pedreiro, sapateiro, seringueiro, sombreiro, tanoeiro, tintureiro e torneiro, e não tinham nada a ver com os chamados "cargos da República", ocupados pelos nobres da cidade. ${ }^{30} \mathrm{Na}$ primeira metade do século XVIII, quando a condição de negociante era bastante desprestigiada em vilas como as de Salvador e Recife, este era o único cargo que esse segmento conseguia alcançar.

$\mathrm{Na}$ segunda metade do século XVIII a condição de negociante atingiu status de nobreza, e em São Paulo há registros dela em cargos de almotaçaria, o que sugere a valorização da função ou a existência de diferenças entre as Câmaras em relação ao prestígio dos cargos.

Em 1814, um requerimento da Câmara cobrava dos almotacés "doutor Nicolau Pereira de Campos Vergueiro e do capitão Manuel Fernandes de Andrade" a importância de 
cruzados de "cabeças de gado das reses dos criadores das licenças que deram visto". ${ }^{31}$ Nicolau Vergueiro, de origem portuguesa, foi um dos principais empreendedores em engenho-de-açúcar e importação de mão-de-obra livre da primeira metade do século XIX, tendo sido um dos representantes de São Paulo na condição de deputado da Constituinte portuguesa de 1821. A patente de capitão era alcançada apenas pelos que detinham fortuna, gerada no comércio ou através da terra ou algum tipo de prestígio, de origem genealógica ou por possuir alguns bens, como cavalos e escravos, e não desempenhar ofício manual.

$M$ anuel Rodrigues Jordão ocupou o cargo de almotacé em São Paulo em 1766, e segundo Nizza da Silva, ante de solicitar, em 1821, a instituição de morgado, já possuía um longo rol de títulos honoríficos: brigadeiro reformado dos Reais Exércitos, comendador da Ordem de Cristo, tesoureiro-geral e deputado da Real Junta da Fazenda de São Paulo, e um dos diretores da Caixa de Descontos, Filial do Banco do Brasil. ${ }^{32}$

Embora ainda não seja possível identificar a origem social e o patrimônio da maioria dos que ocuparam o cargo de almotacé na cidade de São Paulo, tendo em vista a fase em que a pesquisa ainda se encontra, o banco de dados organizado com os nomes desses oficiais revelou que parcela ínfima envolveu-se nas arrematações de contratos vicinais de comércio.

Apenas um indivíduo, que arrematou em 1773 o corte do açougue da cidade das terças-feiras ocupou este cargo em 1784; um alferes, que arrematou um contrato de estanco da freguesia de Santo Amaro também em 1773 ocupou o cargo sete vezes $(1769,1770,1782,1785,1791,1793,1797)$. No contrato das aguardentes, dois desempenharam a função, um em 1765 e 0 outro por cinco vezes $(1770,1782,1791,1793,1797)$. As almotaçarias não coincidiram com os arremates de contratos. $\mathrm{N}$ as casinhas não houve registros de arrematadores que ocuparam esta função.

Dos fiadores dos arrematadores, nenhum fiador do corte do açougue, aguardentes ou casinhas desempenhou a função de almotacé, mas dos fiadores dos estanqueiros, quatro ocuparam a função, sendo um tenente. Ou seja, dos 52 fiadores dos 
arrematadores de estanco, apenas quatro foram almotacés $(7,6 \%)$.

A princípio estes dados sugerem que a tendência era de os oficiais da Câmara ligados ao abastecimento compreenderem um segmento específico, interessado nas obrigações, propinas, emolumentos ou prestígio que pudessem auferir do cargo ocupado. Embora a segunda metade do século XVIII tenha sido marcada pela valorização da atividade mercantil, atribuindo status ao negociante, isto não se estendia ao comércio a retalho, ou seja, de abastecimento e em loja.

Como a função de almotacé pode ter tido valores diferentes entre as Câmaras, a ponto de em São Paulo homens de prestígio terem sido almotacés, é possível que os que ocupavam esta função optassem, em sua maioria, por não diluir o status do cargo em contratos e negócios no mercado vicinal.

Os arrematadores deste circuito, por sua vez, também formavam um grupo com interesses próprios, atuando conforme perspectivas de perdas e vantagens oferecidas pelos circuitos mercantis vicinal ou inter-regional. Em alguns contextos, as inúmeras reclamações da Câmara, em relação à dificuldade para arrematar os contratos do circuito vicinal de comércio, levam a pensar sobre a possibilidade dos potenciais negociantes arrematadores desses contratos se desviarem para uma atuação subsidiária ao circuito de abastecimento inter-regional.

De início, pode-se considerar que esses arrematadores não tinham o prestígio dos grandes negociantes, mas estavam inseridos numa esfera mercantil do organismo econômico colonial que permitia margens de ganhos significativas. Ainda é preciso investigar, entretanto, em que medida o grande ou médio negociante não se envolveu no circuito vicinal de comércio, quando via perspectivas de remuneração.

O Senado da Câmara, através da atuação dos almotacés, procurou fortalecer sua capacidade de competição com os grupos econômico-sociais que se vinculavam, efetiva ou temporariamente, com os circuitos regionais de comércio, e ampliar sua margem de controle sobre o mercado vicinal, movido pela obrigação moral de alimentar os súditos, relações de poder e necessidade orçamentária. Com isto, empreendeu 
determinadas ações visando a enfrentar as fases de crise, expansão e retração do circuito vicinal de abastecimento.

0 registro da receita e despesa da Câmara é a principal fonte que permite traçar hipóteses e questões sobre seu foco de interesses e poder; contudo, nem sempre o pesquisador encontra estes registros, que podem não ter sido preservados ou produzidos sistematicamente.

Para o caso de São Paulo, não foram encontrados registros que englobassem todo o período 1765-1822, mas apenas 0 período 1804-1821, com algumas lacunas. Os documentos intitulados "Receita e Despesa" foram reunidos no conjunto documental encadernado como "Papéis Avulsos". Tais dados, embora devendo ser analisados levando em consideração suas limitações, como possíveis arredondamentos, omissões e erros de cálculo dos escrivães, possuem certa coerência e, relacionados com a documentação qualitativa, são indicadores relevantes.

Dos rendimentos da Câmara de São Paulo transcritos na tabela abaixo, no período 1804-1821, percebe-se que as arrematações dos quatro ramos vicinais de abastecimento - corte do açougue, aguardentes, estancos e casinhas - eram a maior parte da sua receita, chegando a alcançar o montante de $80,9 \%$ a $91,9 \%$. Logo, este era um circuito que tendia a ser catalizador dos interesses da administração local.

Dos onze anos registrados percebe-se uma evolução irregular da porcentagem de recursos gerados nas arrematações no mercado vicinal de abastecimento, ocorrendo momentos de el evação e queda.

Em alguns momentos a renda total das arrematações foi superior em relação ao período anterior, como ocorreu em 1805, 1808,1812 , mas sua porcentagem em relação à renda total foi inferior. Tal situação pode estar relacionada à inflação dos valores pagos nas arrematações em virtude de concorrência entre os negociantes-arrematantes, que poderiam estar vislumbrando perspectivas de ganhos no mercado local ou pressões da Câmara, que se negava a aceitar preços estabelecidos pelos negociantes.

O Senado tendia a ser mais intransigente em relação aos ramos do comércio vicinal mais lucrativos, como o das casinhas, 
do corte da carne e aguardentes. Em 1808 negou-se a arrematar os contratos das aguardentes pelo valor de 90\$000, considerando-o muito diminuto em relação aos anos anteriores. Caso não houvesse arrematante, propunha que 0 próprio Conselho o administrasse, algo que não foi necessário, pois conseguiu alcançar o preço de $300 \$ 000$. Em relação aos outros ramos, como os estancos nas freguesias, o Senado era mais flexível, alegando "a dificuldade que oferece a sua administração e a insignificância do respectivo provento".

TABELA 2 - Rendimento da Câmara produzida através do levantamento de dados nas Atas da Câmara (1765-1822) e Papéis Avulsos (18031822)

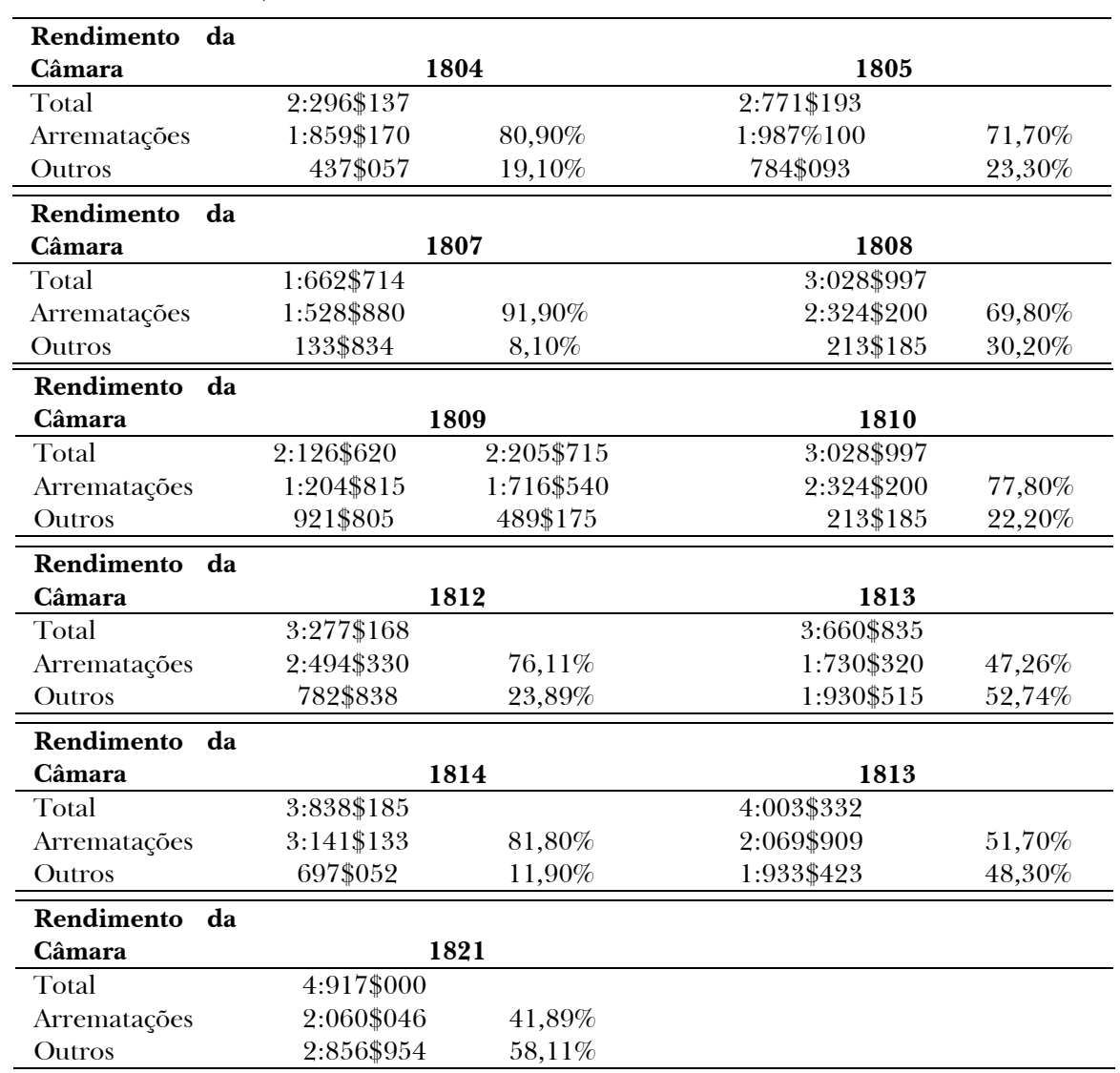


A rápida elevação do valor pago na arrematação do contrato das aguardentes, logo após decisão da Câmara de gerenciar este negócio, leva a pensar sobre a possibilidade dos potenciais arrematadores não responderem, a princípio, aos editais de arrematação, visando a provocar a queda dos seus valores e com isto ampliar suas margens de ganho num mercado, o de comestíveis e bebidas, que tinha público consumidor garantido. Em inúmeros requerimentos ao governo-geral, a Câmara reclamou da dificuldade em arrematar seus contratos.

Se os preços das arrematações dos contratos do mercado vicinal de abastecimento eram inflacionários significa que a cidade de São Paulo também era um mercado consumidor significativo, que despertava interesses e apresentava perspectivas de ganho aos negociantes. As tabelas 3, 4 e 5 de fato comprovam que os três principais ramos vicinais do comércio da cidade: aguardentes, casinhas e corte do açougue sofreram elevações de preços.

TABELA 3 - valores de contratos das casinhas (1773-1822) ${ }^{34}$

\begin{tabular}{cc}
\hline \multicolumn{2}{c}{ Contrato das casinhas } \\
\hline Ano & Valor \\
\hline 1773 & $32 \$ 000,120 \$ 000$ e $91 \$ 895$ \\
1774 & $120 \$ 400$ \\
1775 & $150 \$ 000$ \\
1784 & $212 \$ 000$ \\
1792 & $355 \$ 000$ \\
1804 & $331 \$ 000$ \\
1805 & $331 \$ 500$ \\
1807 & $350 \$ 600$ \\
1808 & $385 \$ 000$ \\
1809 & $385 \$ 500$ \\
1810 & $400 \$ 000$ \\
1812 & $445 \$ 100$ \\
1813 & $422 \$ 000$ \\
1814 & $511 \$ 000$ \\
1815 & $203 \$ 980$ \\
1816 & $400 \$ 000$ \\
1821 & $730 \$ 627$ \\
1822 & $453 \$ 75$ \\
\hline
\end{tabular}


Tabela 4 - Valores dos contratos de aguardentes

\begin{tabular}{cr}
\hline \multicolumn{1}{c}{ Contrato das aguardentes } \\
\hline Ano & Valor \\
\hline 1766 & $32 \$ 000$ \\
1766 & $52 \$ 000$ \\
1767 & $52 \$ 100$ \\
1769 & $52 \$ 500$ \\
1772 & $60 \$ 200$ \\
1773 & $51 \$ 200$ \\
1774 & $44 \$ 100$ \\
1792 & $64 \$ 500$ \\
1804 & $275 \$ 000$ \\
1805 & $371 \$ 000$ \\
1808 & $300 \$ 000$ \\
1809 & $342 \$ 100$ \\
1810 & $320 \$ 000$ \\
1812 & $470 \$ 500$ \\
1814 & $660 \$ 500$ \\
1815 & $280 \$ 500$ \\
1821 & $1: 110 \$ 184$ \\
1822 & $1: 138 \$ 794$ \\
\hline
\end{tabular}

TABELA 5 - Contratos de corte do açouge da cidade de

\begin{tabular}{cr}
\multicolumn{2}{c}{ São Paulo (1765-1822) } \\
\hline Ano & Valor do açougue da cidade \\
\hline 1765 & $128 \$ 000$ \\
1766 & $16 \$ 000$ \\
1767 & $65 \$ 000$ \\
& $160 \$ 000$ \\
1770 & $105 \$ 000$ \\
1772 & $115 \$ 000$ \\
1773 & $16 \$ 000$ \\
& $25 \$ 600$ \\
1774 & 2 dobras \\
1778 & $1 \$ 779$ \\
1780 & $200 \$ 035$ \\
1788 & $126 \$ 000$ \\
1804 & $982 \$ 000$ \\
1805 & $892 \$ 800$ \\
1807 & $745 \$ 170$ \\
1808 & $800 \$ 000$ \\
1809 & $800 \$ 000$ \\
1810 & $702 \$ 800$ \\
1812 & $946 \$ 800$ \\
1813 & $1: 048 \$ 800$ \\
1814 & $1: 004 \$ 800$ \\
1815 & $827 \$ 200$ \\
1821 & $914 \$ 880$ \\
1822 & $880 \$ 840$ \\
\hline
\end{tabular}


Especialmente a arrematação do contrato das casinhas e do corte do açougue sofreu elevação dos preços no ano de 1808, justamente um momento no qual o Rio de Janeiro recebia a família real e todo um séqüito de súditos e funcionários que ampliaram o mercado consumidor de gêneros alimentícios da cidade e abriram novas perspectivas de ganho para os negociantes de alimentos.

Ainda assim, contudo, o mercado consumidor da cidade apresentou perspectivas de ganho, pois a elevação do preço da arrematação indica que houve concorrência entre negociantes interessados em arrematar no circuito vicinal.

Observando a segunda tabela - relativa ao rendimento da Câmara -, nota-se que o movimento dos valores arrecadados no circuito vicinal de abastecimento foi de alta e baixa. Os anos de maior rendimento (1804-05-08-10-12-14) podem estar relacionados às possibilidades de ganho no mercado local, levando os negociantes a concorrerem na arrematação ou a uma reação mais vigorosa da Câmara, visando a inibir outros circuitos de comércio, como o inter-regional, levando os negociantesarrematadores da cidade a verem vantagens em arrematar nos ramos vicinais de abastecimento.

Pelo menos quatro dos grandes circuitos econômicos interregionais - a nordeste pelo vale do Paraíba; para o norte por Campinas e Mogi-M irim, em direção a Minas Gerais e Goiás; para sudoeste, por Sorocaba e I tapetininga e para o caminho do $M \mathrm{ar}^{35}$ - convergiam para São Paulo e a passagem de um a outro obrigava a cruzar a cidade, o que favorecia a ação das autoridades municipais, como os almotacés, para inibir o atravessamento de cargueiros de alimentos e seu desvio para a venda em outros mercados, que não o vicinal. Tais autoridades tendiam a pressionar para que o gado fosse cortado no açougue da cidade e os mantimentos se dirigissem para a venda nas casinhas.

No que diz respeito aos anos de menor rendimento dos contratos de arrematação - 1807-09-13-15 -, pode ter ocorrido intensificação dos circuitos inter-regionais de comércio, estimulada pela transmigração da família real para o Brasil e seu estabelecimento no Rio de Janeiro, e maior insistência dos 
negociantes em tentar driblar o controle das autoridades municipais. Além disso, a política exportadora da capitania, desde o governo geral de Bernardo José de Lorena (1788-1797), vinha tendendo a valorizar os circuitos mercantis inter-regionais, principais fontes de renda da Fazenda Real, e para tanto procurou centralizar as atividades comerciais no porto de Santos, mesmo diante das contestações das vilas de Ubatuba e S. Sebastião.

O Senado da Câmara, então, passou a sofrer uma série de reveses num dos seus principais foco de interesses, ou seja, 0 circuito vicinal de abastecimento, pois desde a segunda metade do século XVIII a política das autoridades régias estabelecidas na capitania foi de estímulo ao comércio inter-regional marítimocosteiro.

Em 1803, para fortalecer ainda mais o comércio marítimo com o Reino, o monopólio santista acima referido foi restaurado e revigorado pelo governador Franco e H orta (1802-1811), o que favorecia os negociantes dessa praça e em especial os contrabandistas que vendiam gêneros alimentícios na América espanhola. ${ }^{36}$

Esta medida levou esse governador ao descrédito e gerou reações do Senado da Câmara visando a fortalecer o circuito vicinal de abastecimento, incentivando as arrematações e combatendo com maior vigor o escoamento da produção de alimentos para os circuitos econômicos inter-regionais, como os terrestres e os marítimo-costeiros, que obrigatoriamente tinham de passar pela cidade para alcançar o ramal Cubatão-serra do Mar.

Tal circuito econômico era de interesse direto da Fazenda Real, e a documentação indica a existência de uma relação tensa e hostil entre as autoridades régias e o Senado da Câmara no que diz respeito à divergência de interesses concernentes aos circuitos mercantis e arrecadações do período.

Num comunicado de 1803, a Junta da Real Fazenda reforçava ao Senado que Ihe cabia continuar apenas arrecadando os rendimentos dos contratos dos novos impostos das vendas, cabendo a ela, Junta, a administração. Reforçava ainda, em tom 
de repreensão, que era necessária cautela em relação a fraudes e extravios. ${ }^{37}$

Nesse mesmo ano, a Junta deliberou sobre a "avultada soma" que o Senado da Câmara deS. Paulo Ihe devia, no valor de "cinco contos trezentos e cincoenta e sete mil oitocentos e noventa e quatro réis", devendo a cada ano pagar 100\$000 para os cofres reais, até que houvesse a amortização do débito.

Enfatizava o governo-geral que era "servido [ordenar] que em conseqüência das positivas ordens que [tinha] mandado expedir a este respeito determinando que a referida Câmara contribua com alguma porção todos os anos até amortizar a dita dívida façais entrar nos cofres reais sem perda de tempo e com a possível brevidade pelo rendimento da sobredita Câmara". ${ }^{38}$

Desde, pelo menos, as duas últimas décadas do século XVIII, uma série de medidas foi tomada no sentido de ampliar os recursos do Estado português em detrimento dos interesses locais. As pressões sobre o Senado da Câmara paulista para cumprir suas obrigações financeiras com o Real Erário faziam parte desse processo.

U ma destas medidas foi a suspensão do monopólio do sal, em 1802, implantada pelo governador-geral Franca e Horta na capitania. A partir de então, o sal ficaria franco no armazém da vila de Santos, podendo a cidade também estabelecer um armazém nos mesmos moldes, "no qual se venda ao povo por miúdo aquela porção de que necessitar e pelo mesmo preço porque nela se acostumou sempre vender, sem que possas alterar nem tampouco embaraçar que outro qualquer negociante 0 venda pelo que lhe parecer". ${ }^{39}$

Com isto beneficiava os interesses da pecuária e, indiretamente, uma das principais fontes da Fazenda Real, ou seja, os circuitos econômicos inter-regionais de animais e carne. Além disso, ao tornar franco o armazém do sal de Santos, incentivava os negociantes desta praça, em detrimento do circuito vicinal. 0 monopólio deu lugar a um sistema de impostos sobre o sal extraído do litoral brasileiro e em alguns pontos do interior. ${ }^{40}$ 
A implantação na capitania do cargo de juiz de fora, nesse mesmo ano, também se inseriu na política real de melhor controlar a administração e arrecadação locais. Afirmava a ordem régia que 0

aumento da população e riqueza de diversas vilas e distritos dos meus domínios da América, multiplicando as relações e complicando os interesses de seus habitantes, tem feito indispensável que para a conservação de sua tranqüilidade interior e para mais prompto comodo e legal decisão de seus pleitos e desavenças se hajam de estabelecer naquelas ditas vilas e distritos, que pela sua maior representação e importância 0 merecerem, juízes letrados que administre justiça aqueles povos e façam amar e respeitar entre eles as leis desta monarquia.

Possivelmente devido à importância da capitania para a Fazenda Real, pedia-se informação "sobre distritos e vilas onde ainda não [existia] juízes de fora e que pela sua população... e pelo estado de sua cultura e comércio precisão para comodidade dos povos, e boa administração da justiça, que nela se criem de novo semel hantes lugares de magistratura". ${ }^{41}$

No ano seguinte, uma notificação real enfatizava a importância da cidade, alegando que ela deveria ser a primeira contemplada com o cargo de juiz de fora, por "ser a capital do Estado, como por abranger em si e no seu termo huma maior população". ${ }^{42}$

Percebe-se, assim, que o circuito vicinal de abastecimento vinha sofrendo pressões e concorrência dos interesses reais, embora isto não tenha se traduzido em significativa queda da receita gerada nas arrematações de contratos, conforme foi notado na coluna de porcentagem da tabela acima, o que sugere ainda a força econômica desse circuito.

Algumas vezes ocorria de Câmara de alguma vila da capitania exigir do governo-geral que forçasse o Senado da Câmara a viabilizar os caminhos, pos era negligenciado-os que se desestimulavam os circuitos inter-regionais.

Atibaia, uma das vias de comunicação subsidiária com o sul de M inas Gerais, voltada para a produção de alimentos, escreveu um ofício ao governador geral, que o encaminhou para o Senado 
da Câmara, exigindo que fossem melhoradas as vias de acesso para São Paulo, pois era desta estrada ligando as duas cidades que os moradores "recebem diariamente os mantimentos precisos para sua subsistência". ${ }^{43}$

Frouxidão e desmando com relação às vias terrestres e de acesso ao ramal caminho do mar-Cubatão-Santos eram características e atitudes da política do Senado, com a finalidade de enfrentar a concorrência do comércio inter-regional e garantir a rentabilidade do circuito vicinal de comércio, pois com isto criava empecilhos para 0 escoamento dos gêneros comercializáveis para outras praças.

Em 1804 o governador-geral Franca e H orta reclamava que, com atitudes como essa se esquecia

por huma parte do cuidado com que devem promover a causa pública e pela outra de animar e facilitar por meio de bons caminhos e a miúdo reparador, o transporte dos efeitos do país, cuja comodidade he uma das circunstâncias essenciais para fazer prosperar o comércio interior e exterior da capitania.

Pedia o governador que não fosse necessário falar mais nesta questão. ${ }^{44}$ Franca e H orta preocupava-se com a fatura e a conservação dos caminhos pelo muito que "influía no comércio geral da capitania". Posteriormente mostrou-se satisfeito com o ofício enviado pelo Senado, informando ter cumprindo suas determinações em relação "a estrada que segue por Juquery para Atibaia", reforçando que ações como estas eram indispensáveis "a todos os caminhos que se dirigem desta capital e dela seguem para o porto de Santos". ${ }^{45}$

O governador-geral, dessa maneira, pregava a favor de um dos principais circuitos do comércio inter-regional, que unia as zonas de comunicação subsidiária do sul de Minas Gerais ao porto de Santos, defendendo interesses ligados ao comércio costeiro e marítimo.

Embora a porcentagem das arrecadações geradas no circuito vicinal ainda fosse alta em 1805, a tendência foi a vigência de um campo de forças entre o Senado da Câmara e as autoridades régias. 0 primeiro aplicava uma política negligente 
com a restauração das vias de acesso à cidade, como forma de dificultar a ligação com o ramal inter-regional serra do $\mathrm{M}$ arCubatão-Santos, e o segundo pressionava pelo cuidado com este ramal.

Desde 1799, o Reino havia aprovado a contribuição voluntária para a construção e o reparo do caminho de Santos. Assim, reforçava o governador-geral

a necessidade de presteza em concluir não só o referido caminho, mas todos os que do interior da capitania tendem a este grande canal da sua importante marinha, de modo a facilitar com comodidade e economia os transportes dos respectivos gêneros e efeitos que podem ser objetos próprios de embarque, que hoje em dia fazem o seu maior artigo de exploração e comércio para o Reino em público benefício do Estado.

Além disso, com o objetivo de fomentar ainda mais o circuito inter-regional, determinou-se que parte dos recursos dessa contribuição voluntária fosse aplicada na construção de ranchos situados na estrada que seguia da vila de I tu até Cubatão, considerados "necessários para a comodidade das tropas e abrigo dos condutores, que diariamente versão por ele com os referidos açucares". ${ }^{46}$

A intensidade adquirida pelo comércio inter-regional, favorecido por circunstâncias históricas, é sugerida pelos dados de rendimento da Câmara do ano de 1808, quando o valor total das arrematações foi superior ao do ano anterior, conforme pode ser visto na primeira tabela, mas a porcentagem dos recursos gerados neste setor caiu bastante (de 91,9\% em 1807 para 69,8\% em 1808), prosseguindo no ano posterior, de 1809, quando foi para $56,65 \%$.

Inflação e concorrência nas arrematações de contratos podem ter gerado a elevação da receita total das arrematações e aumento da geração de receita através de outras fontes, como créditos de anos anteriores, pagamentos de multas, envio de recursos das Câmaras de outras vilas, e podem ter provocado a diminuição da sua porcentagem em relação aos outros rendimentos. 
A hipótese da concorrência nas arrematações sugere que existia mercado consumidor vantajoso na cidade de São Paulo, mas não elimina a possibilidade de outros mercados estarem oferecendo vantagens superiores, a ponto de estimular o desvio dos interesses dos negociantes-arrematadores.

Em 1811, um ofício da Câmara creditava a diminuição do valor oferecido pelos negociantes para a arrematação do contrato das aguardentes por venderem 0 produto na vila de Santos. ${ }^{47}$ Neste mesmo ano, o reverendo padre capellão da Legião de Tropas da cidade, Antônio José Lessa, foi notificado pelo Senado para que se abstivesse de atravessar farinhas de trigo, destinadas ao consumo da cidade, levando-as para "negócio a vila de Santos e Rio de Janeiro". ${ }^{48}$

Assim, a recuperação da receita da Câmara oriunda das arrematações entre os anos 1810-12 pode dizer respeito à reação desta visando a intensificar o controle sobre as arrematações vicinais e impor obstáculos aos circuitos inter-regionais.

Em 1807, quando ainda a porcentagem de recursos gerados nos contratos de arrematações era elevada, a Câmara criou 0 cargo de "tesoureiro das contribuições das pontes", especialmente para o aterrado e ponte do Carmo, via de acesso para o Rio de Janeiro.

0 trabalho deste tesoureiro era intenso aos domingos, quando se emitiam muitos bilhetes. Com isto estabelecia-se certo controle sobre uma das principais vias de atuação dos atravessadores, que desviavam cargueiros de alimentos para serem negociados em outras praças, tidas como mais lucrativas, como a Corte. Ao instalar uma autoridade fiscal nas pontes, a Câmara também combatia a venda da carne cortada fora do açougue público, um dos principais ramos do comércio vicinal da cidade.

A concorrência com o ramo inter-regional, controlado pelas autoridades régias, vinha desde a segunda metade do século XVIII, levando a Câmara a periodicamente adotar medidas mais fiscalizadoras, que se intensificavam em períodos de queda nas arrecadações. 
U ma das medidas adotadas foi combater a aquisição de gêneros de abastecimento fora das casinhas, o mercado público. Com isto, atingiam-se diretamente os atravessadores vinculados ao comércio inter-regional, que se colocavam nos caminhos e pontes da cidade. Um ofício chegou a aconselhar os almotacés que não proibissem a compra de mantimentos para a exportação, sugerindo, portanto, que isto ocorria, mas que apenas se evitasse a compra dos gêneros "fora do lugar indicado". ${ }^{49}$

De fato, as Câmaras das vilas de N ova Bragança e Atibaia representaram ao juiz de fora contra as "violências com que os almotacés desta cidade [São Paulo] vexavão os lavradores, negociantes e comboieiros daqueles conselhos, obrigando-os como lhes parecia a venderem nas casinhas desta dita cidade os seus frutos quase sempre por miúdo".

Pediam que fosse observado o capítulo da correição de 1812, que estabelecia a "franqueza do comércio", podendo os "lavradores, negociantes e comboeiros vender por grosso e por miúdo dar em pagamento ou por qualquer outra forma contratarem e alhearem os frutos e produções de sua lavoura e indústria nesta cidade, na vila de Santos ou onde melhor Ihes convier."

0 ano de 1821 representou um importante momento de inflexão no circuito vicinal de abastecimento e, portanto, nos interesses do Senado da Câmara, pois foi extinta sua autoridade de realizar arrematações de contratos e intensificaram-se os conflitos entre esta instituição e o Real Erário e as autoridades reais.

Ainda assim existia um quadro de inflação no valor das arrematações, o que sugere que havia concorrência entre os negociantes do circuito vicinal de abastecimento e o interesse do Senado em manter controle sobre os principais ramos do comércio que analisados individualmente, tiveram supervalorização, conforme pode ser notado nas tabelas. Um ofício do governo provisório, de outubro de 1821, porém determinava que a Câmara extinguisse todos os estanques (monopólios).

Um almotacé expressou seu temor em comprometer-se com as autoridades reais, como o ouvidor, o corregedor da 
Comarca e o governador-geral, ao seguir as determinações do Senado relativas ao controle do mercado vicinal de abastecimento. Ainda em 1821 era determinado ao almotacé que, em nome do abastecimento local, deveria embaraçar a ação dos carregadores que levavam alimentos para a vila de Santos e para fora do País, cobrando-Ihes tributos mesmo que não dessem entrada nas casinhas. ${ }^{52}$

O circuito vicinal de abastecimento da cidade concentrava interesses do Senado da Câmara de São Paulo e em certa medida, de acordo com a dinâmica do mercado, de um segmento de negociantes-arrematadores. M esmo com a existência de circuitos terrestres e marítimo-costeiros cada vez mais vantajosos, existia um mercado consumidor na cidade que oferecia perspectivas de ganho, levando os negociantes a concorrerem nas arrematações, como demonstram as fases de elevação dos valores dos arremates.

A concorrência com os promissores circuitos interregionais, contudo, foi uma realidade que levou o Senado da Câmara a se mobilizar, cobrando maior eficiência dos almotacés, empreendendo uma política negligente de conservação de estradas e caminhos, especialmente em relação ao caminho do mar, combatendo os atravessadores de alimentos e sustentando uma política hostil e divergente de interesses em relação às autoridades régias.

A vitória do segmento representado pelo comércio interregional, a partir de 1822, parece sugerida pela representação do governo provisório, assinada apenas pelo ex-governador-geral e então presidente João Carlos de d'Oeynhausen e os irmãos Andradas, representantes e originários de famílias de negociantes da vila de Santos.

Acolhiam o requerimento de Jeronymo Pinelli, que se queixava dos estanqueiros das freguesias da cidade, de 0 "embaraçarem e a muitas outras pessoas de venderem comidas e bebidas nas festas públicas". Ordenavam as novas autoridades, que muito se aproximaram da nova ordem e muito se antipatizaram perante os grupos locais de poder, que todos os estancos deveriam ser extintos. ${ }^{53}$ A sedição de 23 de maio de 1822 


\section{pode ter sido a última reação dos interesses radicados no circuito} vicinal de abastecimento da cidade de São Paulo.

MOURA, Denise A Soares de. Local power and the functioning of the vicinal of the commerce in the city of São Paulo (17651822). História, São Paulo, v.24, n.2, p.261-290, 2005.

ABSTRACT: This text presents some hypothesis and ideas about the provisioning commerce in the city of São Paulo, among the years 1765-1822, through quantitative and qualitative conditions found in two documental collections produced by Senate of chamber: memoranda and detached papers. This commerce is understood like one the circuits of colonial organism, like proposed by José Roberto do Amaral Lapa. Thereby, it has been noted its autonomous functioning, according to the floods of the internal market, the actions of the contracts bidding-merchants and the reactions of the Senate of town chamber São Paulo in order to face its contexts of crisis and the radicalism of power relations a round this mercantil circuit, like an arousing factor of disputes and hostilities among local political interests, biddingmerchants and royal authorities.

KEYWORDS: internal commerce; local power; businessmen.

\section{NOTAS}

\footnotetext{
* Dep. de História, UNESP, campus de Franca, São Paulo, Brasil. Este artigo contêm resultados preliminares de uma pesquisa que conta com um auxílio de pesquisa concedido pelo CNPq em julho de 2005, através do Edital Ciências Humanas, Sociais e Sociais Aplicadas/2004. CEP 14400- 690 . e-mail: dmsoa@bol.com.br

${ }^{1}$ Desde agosto de 2005 esta pesquisa vem contando com um auxílio concedido pelo CNPq, através do Edital Ciências Humanas, Sociais e Aplicadas/2004.

${ }^{2}$ Clássicos sobre o caráter específico português no enfrentamento da crise do Antigo Regime são: Novais, Fernando A. Portugal e Brasil na crise do Antigo Sistema Colonial (177-1808). 5 ${ }^{\mathrm{a}}$ ed., SP, Hucitec, 1989 e Falcon, Francisco José
} 
Calazans. A época pombalina: política econômica e monarquia ilustrada. 2.ed. São Paulo: Ática, 1993.

${ }^{3}$ Bellotto, Heló́sa Liberalli. Autoridade e conflito no Brasil colonial: o governo do Morgado de Mateus em São Paulo: 1765-1775. São Paulo: Conselho Estadual de Artes e Ciências Humanas, 1979, p.40.

${ }^{4}$ BRUNO, Ernani da Silva. História e tradições da cidade de São Paulo. 4 ed. São Paulo: Hucitec, 1991, 3.v; TAUNAY, Alfredo D'Escragnolle. A cidade de São Paulo no século XVIII. São Paulo: Divisão do Arquivo Histórico, 1951.

${ }^{5}$ Esta metodologia de trabalho foi elaborada a partir da leitura de GRASSBY, Richard. The business community of seventeenth-century England. Cambridge: Cambridge University Press, 1995 e Kinship and capitalism: marriage, family and business in the English-Speaking World, 1580-1740. United Kingdom: Woodrow Wilson Center/Cambridge University, 2001.

${ }^{6} \mathrm{O}$ autor fala em "economias regionais de uma mesma colônia" e a análise dos dados permitiu identificar este circuito mais infiltrado na colônia o qual se denomina circuito vicinal, diretamente subordinado às Câmaras. LAPA, José Roberto do Amaral. O sistema colonial. São Paulo: Ática, 1991, p.69. Este circuito se relaciona ainda ao que pioneiramente Maria Yedda Linhares denominou "problema do abastecimento". Cf. Linhares, Maria Yedda. História do abastecimento: uma problemática em questão (1530-1918). Brasília: BINAGRI, 1979.

${ }^{7}$ Lapa, José Roberto do Amaral. Op. cit., pp. 62-3.

8 Xavier, Ângela e Hespanha, António Manuel. As redes Clientelares. In: Hespanha, António Manuel. História de Portugal: o Antigo Regime (16201807). Lisboa: Editorial Estampa, 1992, p. 381.

${ }^{9}$ Idem, p. 382.

${ }^{10}$ Fragoso, João. A formação da economia colonial no Rio de Janeiro e de sua primeira elite senhorial (séculos XVI e XVII). In: Fragoso, J. (org.). O Antigo Regime nos trópicos: a dinâmica imperial portuguesa. Rio de Janeiro: Civilização Brasileira, 2001, p.47.

${ }^{11}$ LINHARES, Maria Yedda Leite. Op. cit., p.84.

${ }^{12}$ BLAJ, Ilana. Mentalidade e sociedade: revisitando a historiografia sobre São Paulo colonial. Revista de História. n.142-3, 2000, p. 243. Cf também BLAJ, Ilana. A trama das tensões: o processo de mercantilização de São Paulo colonial (1681-1721). São Paulo: Humanitas, FFLCH-USP, FAPESP, 2002 e FERNANDES, Florestan. A sociedade escravista no Brasil. In: Circuito fechado. São Paulo: Hucitec, 1976.

${ }^{13}$ Não foi à toa que o Barroco encontrou campo fértil para aclimação e criação na sociedade do Brasil-colônia. Cf. D’AVILA, Affonso. O lúdico e as projeções do mundo barroco. 3.ed. São Paulo: Perspectiva, 1994, 2.v.

${ }^{14}$ SILVA, Maria Beatriz Nizza. Ser nobre na colônia. São Paulo: Unesp, 2005.

${ }^{15}$ Idem, p.321. 
${ }^{16}$ Idem, p. 141.

${ }^{17}$ Idem.

${ }^{18}$ BOXER, Charles. Conselheiros municipais e irmãos de caridade. In:

O Império Marítimo português. Trad. Anna Olga de Barros Barreto. São Paulo: Cia das Letras, 2002, p.286. Cf. também, do mesmo autor Portuguese Society in the tropics: the Municipal Councils of Goa, Macau, Bahia and Luanada, 15101800. Madison: University of Wisconsin Press, 1965.

19 MONTEIRO, Nuno Gonçalo. Os concelhos e as comunidades. In: HESPANHA, Antonio Manuel. História de Portugal: o antigo regime (16201807). Lisboa: Editorial Estampa, 1992. Cf. também HESPANHA, António Manuel. As vésperas do Leviathan: instituições e poder político, Portugal - século XVII. Coimbra: Almedina, 1994.

${ }^{20}$ BOXER, Charles. Conselheiros municipais... Op. cit., p.291.

${ }^{21}$ PRADO JR., Caio. Formação do Brasil Contemporâneo. São Paulo: Martins, 1942, p.316-17.

${ }^{22}$ BLAJ, Ilana. Mentalidade e sociedade...Op. cit., p.254.

${ }^{23}$ BICALHO, Maria Fernanda. As Câmaras Municipais no Império Português. O exemplo do Rio de Janeiro. Revista Brasileira de História, v.18, n.36, 1998, p.258. A cidade e o Império: o Rio de Janeiro no século XVIII. Rio de Janeiro: Civilização Brasileira, 2003.

${ }_{24}^{4}$ TAUnAY, A. E. História da cidade de S. Paulo. São Paulo: Divisão do Arquivo Histórico, 1951, p.117-123.

${ }^{25}$ Papéis Avulsos, v.16, 1821, p.295-318.

${ }^{26}$ SANT'ANNA, Nuto. As casinhas (o primeiro mercado de S. Paulo). Revista do Arquivo Municipal de S. Paulo, n.XVI, 1935, p.71.

${ }^{27}$ Documentos Interessantes, v.19, p.90. apud TAUNAY, A. E. História da cidade de S. Paulo no século XVIII. São Paulo: Divisão do Arquivo Histórico, 1951, p.117123.

${ }^{28}$ SALGADO, Graça. Fiscais e meirinhos: a administração no Brasil colonial. Rio de Janeiro: Nova Fronteira, 1985.

${ }^{29}$ Atas da Câmara, v.15, 1777, p.54-55.

${ }^{30}$ SILVA, Maria Beatriz Nizza. Op. cit., p.20.

${ }^{31}$ Atas da Câmara, v. 21, 1814, p.459.

${ }^{32}$ SILVA, Maria Beatriz Nizza. Op. cit., p.310.

${ }^{33}$ Papéis Avulsos, v.7, 1808, p.1.

${ }^{34}$ As tabelas 4, 5 e 6 foram produzidas através do levantamento de dados nas Atas da Câmara (1765-1822) e Papéis Avulsos (1803-1822)

${ }^{35}$ PRADO JR., Caio. O fator geográfico na formação e no desenvolvimento da cidade de São Paulo. In:

São Paulo: Brasiliense, 1972, p.103.

${ }^{36}$ HOLANDA, Sérgio B. São Paulo, História Geral da Civilização Brasileira. 6.ed., Rio de Janeiro: Bertrand Brasil, 1995, t.2, v.II, p.422. 
${ }^{37}$ Papes Avulsos. v.4, 1803, p.83.

${ }^{38}$ Idem, p.88.

${ }^{39}$ Idem, p.57.

${ }^{40}$ ALDEN, Dauril. O período final do Brasil-colônia: 1750-1808. In: BETHEL, Leslie (org.). História da América Latina. Trad. Mary Amazonas Leite e Magda Lopes. São Paulo; EDUSP, Brasília: Fundação Alexandre de Gusmão, 1999, p.554.

${ }^{41}$ Papéis Avulsos. v.5, 1802, p.15.

${ }^{42}$ Idem, p.13.

${ }^{43}$ Idem, p. 20.

${ }^{44}$ Idem, p.4.

${ }^{45}$ Idem, p. 1.

${ }^{46}$ Idem, p. 108

${ }^{47}$ Idem. v.9, 1811 , p.285.

${ }^{48}$ Idem, p.302.

${ }^{49}$ Idem. v.11, 1814, p.203.

${ }^{50}$ Idem, v. 14, 1819, p. 258.

${ }^{51}$ Atas da Câmara, v.22, 6/10/1821, p.521.

${ }^{52}$ Papéis Avulsos, v.16, 27/3/1821, p.54.

${ }^{53}$ Idem, p. 226.

Artigo recebido em 06/2006. Aprovado em 07/2006. 